\author{
돼지의 번식형질과 산육형질에 대한 유전모수 추정 \\ 조충일 $^{1} \cdot$ 안진국 $^{2} \cdot$ 이준호 $^{3} \cdot$ 이득환 $^{3}$ \\ ${ }^{1}$ 농촌진흥청 축산과학원, ${ }^{2}$ 삼화육종, ${ }^{3}$ 국립한경대학교
}

\title{
Genetic Parameter Estimates for Reproductive and Productive Traits of Pig in a Herd
}

\author{
Chungil Cho ${ }^{1}$, Jinkuk $\mathrm{Ahn}^{2}$, Joonho Lee ${ }^{3}$ and Deukhwan Lee ${ }^{3}$ \\ ${ }^{1}$ National Institute of Animal Science, R.D.A., \#9 Eoryong-ri, Seonghwan-eup, Cheonan-si, Chungcheongnam-do, 331-801, \\ Rep. of Korea. ${ }^{2}$ Samhwa breeding agriculture incorporation. 3-2, Sinjuk-ri, Cheonbuk-myeon, Boryeong-si, \\ Chungcheongnam-do, Rep. of Korea. ${ }^{3}$ Department of Animal Life Resources, Hankyong National Univ. Seokjeong-dong \\ Anseong-si Gyeonggi-do, 456-749, Rep. of Korea
}

\begin{abstract}
The purpose of this study was to estimate heritabilities and genetic correlations for reproductive and productive traits and to apply their estimates to selection strategies in a swine population. Reproductive and productive traits considered in this study were number of born alive piglet (NBA), number of weaned piglet (NW), loin eye area (LEA), days to $90 \mathrm{~kg}$ (D90KG), back fat thickness (BF), and lean meat content (LEAN). Data were collected from 9,886 litters on 2,447 sows for reproductive traits and 10,181 gilts and boars for productive traits from Jan. 2000 to Dec. 2008 in a swine GGP farm. The statistical model to estimate genetic parameters for considering traits was a multiple traits animal model with including animal and maternal additive effects and litter effects on reproductive traits and animal additive effects on productive traits as random as well as some of fixed effects. For estimating (co) variance components of several random effects, restricted maximum likelihood methodology was used on this assumed model. The estimated heritabilities by animal additive effects and maternal effects were 0.07 and 0.02 for NBA and 0.03 and 0.02 for NW, respectively. Genetic correlation estimate for direct genetic effects between NBA and NW was 0.14 . Heritability estimates for direct genetic effects were $0.19,0.39,0.36$, and 0.43 for LEA, D90KG, BF and LEAN, respectively. The genetic correlation of LEA with LEAN was 0.35 . Productive traits were antagonistically correlated with reproductive traits. From these results it is concluded that, if selection is done for strong positive effects of reproductive traits, then this would decline productive performance.
\end{abstract}

(Key words : Genetic parameters, Reproductive traits, Productive traits, Pig, Swine breeding)

$$
\text { 서 론 }
$$

최근 바이오 연료생산 확대, 이상기후 및 중국, 인도 등 신흥개 발도상국의 경제성장에 따른 육류의 소비증가로 사료곡물가격이 지 속적으로 상승하고 있으며, 대외적으로 한국과 미국, 한국과 유럽 연합 $(\mathrm{EU})$ 간의 자유무역협정이 타결되면서 저렴한 양질의 육류수입 으로 인한 양돈농가의 어려움이 증가될 것으로 우려된다. 이와 같 이 어려운 양돈산업 현실에서 양돈농가가 생존하기 위해서는 유전 적으로 우수한 개체를 선별하여 사료효율을 극대화 하고 $\mathrm{MSY}$ (Market pigs per Sow per Year)의 개량을 통한 양돈농가의 경쟁 력 확보가 필요하다. 일반적으로 돼지의 등심단면적, 등지방두께, $90 \mathrm{~kg}$ 도달일령 및 정육률 등과 같은 산육형질과 복당 실산자수
및 이유자돈수 등과 같은 번식형질 등은 돼지의 중요한 경제형질들 로써 유전적 개량을 통하여 유전능력을 향상시키려는 노력이 많이 이루어져 왔다. 이러한 산육형질과 번식형질 간에는 일반적으로 부 의 유전상관이 존재하거나(Clutter and Brascamp, 1998; Holm 등, 2004) 또는 상호 관련성이 거의 없는 것으로 보고되고 있다 (Ducos and Bidanel, 1996; Rydhmer, 2000; Chen 등, 2003b). 또한 돼지의 번식형질들은 상가적 유전효과뿐만 아니라 모체로부터 유전효과를 갖는 것으로 알려져 있으나, 국내 연구에서는 자료수집 의 한계 및 분석방법의 복잡성으로 인하여 이에 대한 연구가 미진 한 실정이다. 따라서 본 연구에서는 특정 종돈업체의 단일농장에서 약 10여년간 선발육종을 통하여 개량한 Landrace, Yorkshire 및 Duroc 등 3품종으로부터 조사된 번식형질과 산육형질들에 대해 다

* Corresponding author: Deukhwan Lee, Department of Animal Life Resources, Hankyong National Univ. Seokjeong-dong Anseong-si Gyeonggi-do, 456-749, Rep. of Korea, Tel: 031-670-5091, Fax: 031-676-5091, E-mail : dhlee@hknu.ac.kr 
형질 혼합모형식을 설정하여 집단의 유전변이 및 형질들간 유전적 상관관계를 추정함으로써 앞으로의 농장단위 선발 및 개량방향 설 정에 지표로 삼고자 본 연구를 실시하였다.

\section{재료 및 방법}

\section{1. 공시자료 및 사전보정}

본 연구에서는 2000 년에 기초축을 도입하여 2008 년까지 개량을 진행한 국내 특정 종돈장에 있는 3품종 (Landrace, Large white, Duroc)의 종돈으로부터 조사된 번식자료와 이들의 자손의 산육검 정자료를 이용하였다. 본 연구에 고려된 번식관련 형질은 실산자수 $(\mathrm{NBA})$ 및 이유자돈수 $(\mathrm{NW})$ 를 이용하였고, 산육관련 형질들은 등 심단면적 $(\mathrm{LEA}), 90 \mathrm{~kg}$ 도달일령 $(\mathrm{D} 90 \mathrm{KG})$, 등지방두께 $(\mathrm{BF})$ 및 정육률 $(\mathrm{LEAN})$ 등을 이용하였다. 실산자수 $(\mathrm{NBA})$ 는 사산, 미라, 체중미달, 기형자돈을 제외한 생존산자수로 정의하여 자료를 조사 하였는데 이용된 번식기록은 모돈 2,477두로부터 9,886복의 분만 및 이유시 자돈수의 자료가 수집되었고 1 산에서 12산까지 산차가 분포되었으며, 산육기록은 1산에서 11산차까지 분포된 10,181두의 등심단면적, $90 \mathrm{~kg}$ 도달일령, 등지방두께와 정육률 데이터를 수집 하였다.

상기의 형질들에 대한 자료는 한국종축개량협회에서 수행하는 검 정계획의 일환으로 수집되었는데 번식성적 검정은 전두수 검정을 실시하였으며, 산육형질들에 대한 자료는 한국종축개량협회 직원이 입회한 농장검정의 일환으로 측정이 이루어졌다. 집단의 평균 90 $\mathrm{kg}$ 도달일령시 체중계 및 도체성적 조사를 위한 $\mathrm{A}$-모드 초음파측 정기 (PIGLOG 105)를 사용하여 실체중, 등지방두께, 등심단면적 및 정육률 등을 측정하여 기록하였다. 도체형질에 대한 측정방법으 로써 등지방두께 실측치는 제 4 늑골, 최후늑골, 최후척추 3 부위를 측정하여 평균을 계산하였고 등심단면적은 최후늑골의 정중선에서 측방 $5 \mathrm{~cm}$ 부위를 측정하였으며, 정육률은 등지방두께 측정치와 등
심단면적 측정치를 이용하여 PIGLOG 기기에서 계산된 값을 이용 하였다. 측정된 데이터는 다음의 보정식에 의해 형질별 보정을 실 시하였다(NIAS, 2010).

$$
\begin{aligned}
& \mathrm{D} 90 \mathrm{KG}=\mathrm{AGE}+\frac{(90-\mathrm{WT})}{\mathrm{WT}} \times(\mathrm{AGE}-38) \\
& \mathrm{BF}=\mathrm{BF}_{\mathrm{m}}+\frac{(90-\mathrm{WT}) \times \mathrm{BF}_{\mathrm{m}}}{(\mathrm{WT}-11.34)} \\
& \mathrm{LEA}=\mathrm{LEA}_{\mathrm{m}}+\frac{(90-\mathrm{WT}) \times \mathrm{LMA}_{\mathrm{m}}}{(\mathrm{WT}-70.31)}
\end{aligned}
$$

여기서 $\mathrm{AGE}$ 는 체중 측정시 일령이며 WT는 실측 체중이고, $\mathrm{LEAm}$ 및 $\mathrm{BFm}$ 은 실측치 등심단면적 및 등지방두께이다. 정육률 에 대한 보정방법은 실체중에 따른 보정을 적용하여 $90 \sim 95 \mathrm{~kg}$ 체 중을 기준으로 매 $5 \mathrm{~kg}$ 씩 증가함에 따라 정육률 실측치에 0.5 를 더 하였으며 기준치에서 매 $5 \mathrm{~kg}$ 씩 감소함에 따라 실측치에서 0.5 씩 감하는 방법으로 보정을 실시하였다. 혈통정보는 기록이 없는 선조 를 포함하여 총 50,582 두의 혈통기록이 이용되었고 품종, 모품종, 성별에 대한 정보는 Table 1에 제시된 바와 같다.

\section{2. 분석방법}

번식형질과 산육형질은 형질에 영향하는 고정효과가 서로 다르기 때문에 SAS 통계 분석프로그램을 이용하여 관측치별 영향하는 환 경요인에 대해 분산분석을 실시하였으며, 이를 바탕으로 번식형질 과 산육형질의 모형식을 아래와 같이 설정하여 유전분석을 실시하 였다. 각 품종별 유전적 특이성이 다르고 품종간의 혈연적 연결성 이 없으며 순수 품종을 육종하기 위하여 품종별 독립적인 선발방법 을 택하고 있기 때문에 본 연구에서 고려된 번식형질 및 산육형질 에 대한 유전분석을 독립적으로 실시함이 합당할 것이다. 하지만 형질간의 유전적 상관, 특히 번식형질과 산육형질간의 유전적 상관 의 크기는 품종간 상이점이 적을 것으로 가정하였으며 이러한 가정

\begin{tabular}{|c|c|c|c|c|c|}
\hline Breed & Number & SS & Number & Sex & Number \\
\hline \multicolumn{6}{|c|}{ Reproductive traits } \\
\hline LL & 1302 & LL & 6414 & & \\
\hline YY & 7833 & YY & 2716 & & \\
\hline DD & 751 & $\mathrm{DD}$ & 756 & & \\
\hline \multicolumn{6}{|c|}{ Productive traits } \\
\hline LL & 1081 & & & Male & 3223 \\
\hline YY & 6303 & & & Female & 6958 \\
\hline DD & 2797 & & & & \\
\hline
\end{tabular}

Table 1. Number of record on reproductive and productive traits by breed, breed of service sire and sex in a swine herd of Korea

SS: breed of service sire; LL = Landrace; YY = Large white; DD = Duroc 
하에 추정치의 정확도를 높이고 형질간의 상관관계를 알아보기 위 하여 각 3 품종을 혼합하여 분석하였다. 따라서 통계적 모형설정에 서 품종의 효과를 고정효과로 간주하고 고려된 형질들에 대한 품종 간 편의현상을 제거하기 위하여 품종의 효과를 고정효과로 모형에 포함시켰으며 개체의 유전효과를 품종내 중첩된 임의효과로 간주하 여 자유도의 감소로 인한 편의현상을 제거하기 위한 모형식을 설정 하였다. 따라서 번식형질 $(\mathrm{NBA}$ 및 $\mathrm{NW})$ 과 산육형질 $(\mathrm{LEA}, \mathrm{D} 90 \mathrm{KG}$, $\mathrm{BF}, \mathrm{LEAN})$ 모두를 동시에 고려한 다형질 평가모형에서 번식형질 에 대한 선형모형식은 다음과 같이 설정하였다.

$y_{i j k l m}=\mu+b_{i}+s_{j}+p_{k}+y_{1}+a_{i j k l m}+m_{i j k l m}+e_{i j k l m}+e_{i j k l m}$

여기서, $\mathrm{y}_{\mathrm{ijkl}}$ 는 각 형질별 관측치이고, 고정효과로써 $\mathrm{b}$ 는 품종효 과이며 $\mathrm{ss}$ 는 교배웅돈효과, $\mathrm{p}$ 는 산차효과, $\mathrm{ys}$ 는 분만시 년도-계절 효과 등이며 임의효과로써 $\mathrm{a}$ 는 개체의 상가적 유전효과, $\mathrm{m}$ 은 모계 의 상가적 유전효과, $\mathrm{pe}$ 는 영구환경효과 및 $\mathrm{e}$ 는 임의 잔차효과이다.

또한 4가지 산육형질에 대한 선형모형은 모두 동일하게 아래와 같이 설정하였다.

$$
\mathrm{y}_{\mathrm{ijklm}}=\mu+\mathrm{b}_{\mathrm{i}}+\mathrm{ys}_{\mathrm{j}}+\operatorname{sex}_{\mathrm{k}}+\mathrm{mp}_{1}+\mathrm{a}_{\mathrm{ijklm}}+\mathrm{e}_{\mathrm{ijklm}}
$$

여기서 $\mathrm{b}$ 는 품종효과이며 $\mathrm{ys}$ 는 분만시 년도-계절효과, sex는 성 의 효과, $\mathrm{mp}$ 는 모산차 효과이며 임의효과로써 $\mathrm{a}$ 는 개체의 상가적 유전효과, 및 $\mathrm{e}$ 는 임의 잔차효과이다.

상기의 두 가지 다른 환경요인을 고려한 다형질 혼합모형식으로 부터 유전분석을 위해 아래와 같은 가정을 설정하였다. 번식형질과 산육형질간의 환경상관은 없고, 실산자수 $(\mathrm{NBA})$ 와 이유자돈수 $(\mathrm{NW})$ 에 있어서 개체 유전효과와 모체유전효과 간에 상관이 없고 각 형질 간 개체 상가적 유전효과에 대한 분산-공분산 성분 $(\mathrm{G})$ 은 다음과 같다고 가정하였으며,

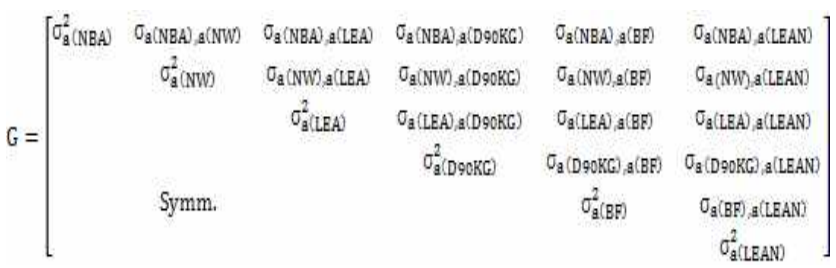

또한 모체 유전효과 $(\mathrm{M})$, 영구환경효과 $(\mathrm{P})$ 및 임의환경효과 $(\mathrm{R})$ 에 대한 각 형질간 분산-공분산 성분은 다음과 같이 가정하였다.

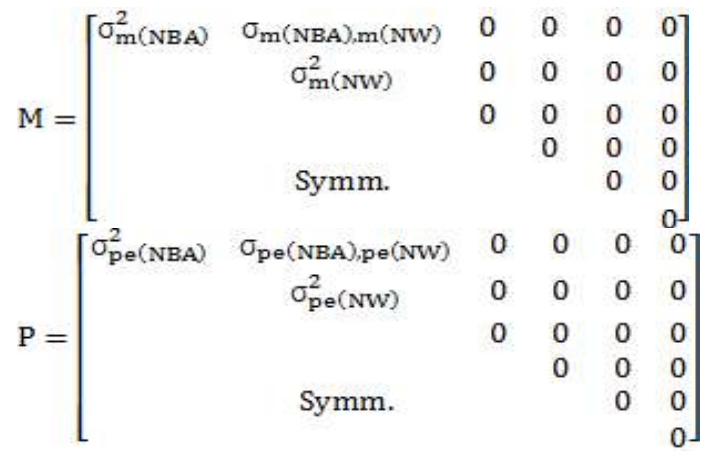

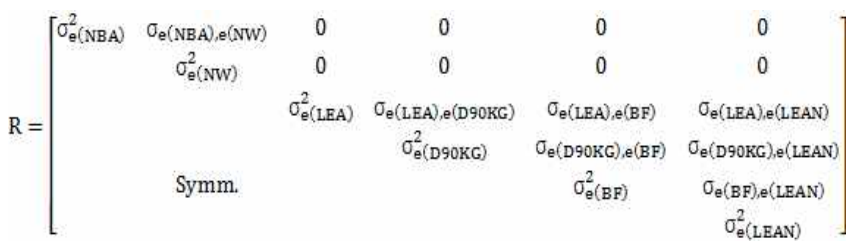

상기의 모형으로부터 통계분석방법은 제한최대우도법 (REML) (Patterson and Thompson, 1971)에 의하였으며 분석프로그램은 BLUPF90 (Misztal, 2001)을 이용하여 해를 추정하여 각형질별 유 전력과 형질간 유전상관을 계산하였다.

\section{결과 및 고찰}

\section{1. 일반능력}

전체 자료에 대한 기초통계량 분석은 Table 2와 같다. Table 2 에 제시된 바와 같이 표현형 관측치에 있어서 실산자수는 10.40 \pm 3.13 두로, 이유자돈수는 $9.21 \pm 1.60$ 두로 나타났다. 산육형질에 대 한 일반능력은 등심단면적에 있어서 $30.55 \pm 3.28 \mathrm{~cm}^{2}, 90 \mathrm{~kg}$ 도달 일령은 $155.44 \pm 13.59$ 일, 등지방두께는 $12.39 \pm 2.03 \mathrm{~mm}$, 정육률은 $59.85 \pm 2.50 \%$ 으로 나타났다.

\section{2. 환경요인 분석}

유전분석을 위한 최적 통계분석 모형을 찾기 위하여 관측치의 편 의 (bias)를 발생시킬 수 있는 환경요인들에 대한 분산분석을 실시 한 결과 번식형질에 영향하는 요인들로써 품종, 교배웅돈, 산차 및 분만시 년도-계절 등이 영향을 미치는 것으로 분석되었다 (Table 3). 특히 품종별 실산자수 및 이유자돈수에서 고도의 유의적인 차 이를 보이고 있었으며 이는 이들형질들에 있어서 품종간 차이가 크 게 있음을 시사한다고 하겠다. 반면에 교배웅돈은 이유자돈수에 유 의적인 영향을 미치지 않는 것으로 분석되었다. 또한 모돈의 분만 년도에 따라 실산자수 및 이유자돈수는 점차 증가하는 경향치를 보 였는데 (Fig. 1) 이는 사양관리가 매년 점차 좋아지고 있거나 유전 적으로 다소의 개량이 진행되는 것으로 추측할 수 있는 결과라 사 료된다. 또한 어미의 산차별 실산자수 및 이유자돈수는 Fig. 2에 제시하였는데 실산자수는 3 4산에서 가장 높은 것으로, 이유자돈수 는 2산차에서 가장 높은 것으로 나타났다. 산육형질에 대한 각 요 인들의 유의성 검정을 분산분석을 통하여 살펴본 결과 (Table 4), 모든 산육형질에 있어서 품종간, 출생시 년도-계절 요인 및 성별 에 따라 $0.1 \%$ 수준에서 유의적인 차이가 있는 것으로 분석되었고, 어미의 산차에 따른 차이는 등심단면적 및 $90 \mathrm{~kg}$ 도달일령은 $1 \%$ 수준에서, 그리고 정육률은 $5 \%$ 수준에서 유의적인 차이가 있는 반 면에 등지방두께는 유의적 차이가 나타나지 않았다. 성별 또는 품 종별 산육형질에 대한 평균은 Table 5에 제시하였는데 등지방두께 및 정육률은 3 품종 모두 유의적인 차이를 보였고 $90 \mathrm{~kg}$ 도달일령 
Cho et al. ; Genetic Parameter Estimates for Reproductive and Productive Traits of Pig in a Herd

Table 2. Simple statistics of reproductive and productive traits in a swine herd of Korea

\begin{tabular}{lcrrrr}
\hline Trait & N & MEAN & SD & MIN & MAX \\
\hline \hline Reproductive traits & & & & & \\
NBA & 9,886 & 10.40 & 3.13 & 1 & 23 \\
NW & 9,864 & 9.20 & 1.59 & 1 & 16 \\
\hline Productive traits & & & & & \\
LEA $\left(\mathrm{cm}^{2}\right)$ & 10,181 & 30.55 & 3.28 & 46.64 & 18.41 \\
D90KG (day) & 10,181 & 155.44 & 13.59 & 251.00 & 111.00 \\
BF (mm) & 10,181 & 12.39 & 2.03 & 24.28 & 6.81 \\
LEAN (\%) & 10,181 & 59.85 & 2.50 & 67.50 & 46.10 \\
\hline
\end{tabular}

NBA : number of piglets born alive; NW : number of weaned piglet

LEA : loin eye area; D90KG : days to $90 \mathrm{~kg}$; BF : back fat thickness; LEAN : lean meat content.

Table 3. Analysis of variances for reproductive traits by sources of effects in a swine herd of Korea

\begin{tabular}{lrcc}
\hline Source & DF & NBA & NW \\
\hline \hline Breed & 2 & $3.99^{*}$ & $15.44^{* * *}$ \\
SS & 2 & $9.29^{* * *}$ & $0.22^{\mathrm{NS}}$ \\
Parity & 11 & $37.87^{* * *}$ & $73.89^{* * *}$ \\
YS & 30 & $27.71^{* * *}$ & $60.77^{* * *}$ \\
\hline
\end{tabular}

SS: breed of service sire; YS: birth year-season effects;

NBA : number of piglets born alive;

NW : number of weaned piglet;

$* * *: p<0.001 * *: p<0.01 *: p<0.05$ NS: non significant.

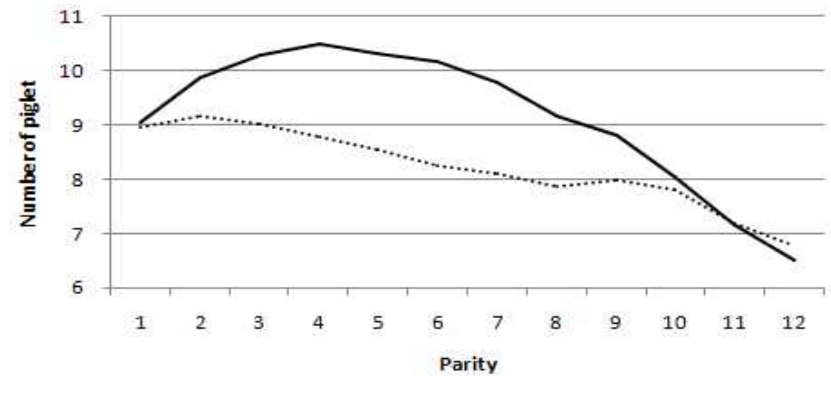

- NBA $\cdots \cdots \cdots$ NW

Fig. 2. Number of piglets born alive (NBA) and weaned (NW) by parities in a swine herd of Korea.

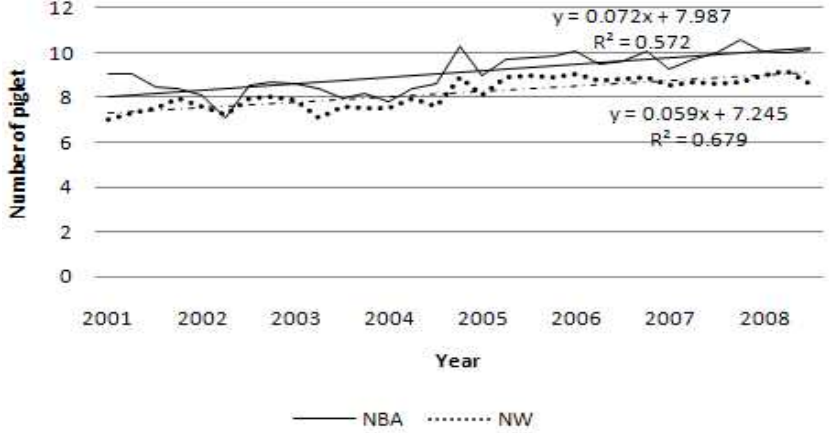

Fig. 1. Number of piglets born alive (NBA) and weaned (NW) by birth year in a swine herd of Korea.

은 Duroc종이 Landrace 또는 Yorkshire종 보다 빠른 것으로 분석 되었다.

\section{3. 유전모수추정}

Table 6에 번식형질 및 산육형질에 대한 유전력, 형질간 유전상
관, 표현형 상관, 번식형질에 대한 모체 유전효과 및 형질간 모체 유전효과의 상관에 대해 나타냈다. 그 결과, 번식형질의 실산자수 에 대한 유전력은 0.07 , 모체 유전효과는 0.02 로 추정되었고 이유 자돈수의 유전력은 0.03 , 모체 유전효과 0.02 로 추정되었으며 이들 두 형질 간의 유전상관은 0.14 , 모체 유전효과에 대한 상관은 0.06 로 추정되었다. 또한 등심단면적의 경우 $0.19,90 \mathrm{~kg}$ 도달일령은 0.39 , 등지방두께 및 정육률은 각각 0.36 및 0.43 으로 번식형질에 비해 높은 유전력을 나타내는 것으로 추정되었다. 또한 등심단면적 과 등지방두께간에는 0.04 로 유전적 상관관계가 거의 없으며, 등심 단면적과 정육률 간에는 0.35 로 중도의 유전적 상관관계를 갖는 것으로 추정되었다. 반면에 등지방두께와 정육률 간은 -0.42 로 중 도의 부의 상관관계를 나타냈으며, 등지방두께와 $90 \mathrm{~kg}$ 도달일령 간에는 유전상관이 없는 것으로 추정되었다. 다른 연구결과들과 비 교하여 보면 $\mathrm{Su}$ 등(2007)은 다형질 모델에서 Landrace, Yorkshire 의 실산자수 유전력은 $0.08,0.05$ 로 각각 추정하여 본 연구와 비슷한 수치의 연구결과를 얻었으며, Chen 등 (2003a)은 단형질 모델에서 Landrace, Yorkshire, Duroc의 실산자수의 유전 력은 각각 $0.08,0.10,0.09$ 로 추정하고 이유자돈수의 유전력은 $0.05,0.05,0.07$ 로 각각 추정하여 본 연구와 비슷한 연구결과를 
Cho et al. ; Genetic Parameter Estimates for Reproductive and Productive Traits of Pig in a Herd

Table 4. Analysis of variances for productive traits by sources of effects in a swine herd of Korea

\begin{tabular}{lrcccc}
\hline Source & DF & LEA & D90KG & BF & LEAN \\
\hline \hline Breed & 2 & $16.74^{* * *}$ & $55.15^{* * *}$ & $288.55^{* * *}$ & $256.05^{* * *}$ \\
Sex & 1 & $460.45^{* * *}$ & $475.15^{* * *}$ & $1077.69^{* * *}$ & $242.20^{* * *}$ \\
Mpar & 10 & $2.44^{* *}$ & $2.53^{* *}$ & $1.09^{\mathrm{NS}}$ & $2.13^{*}$ \\
YS & 27 & $129.34^{* * *}$ & $32.57^{* * *}$ & $41.78^{* * *}$ & $75.11^{* * *}$ \\
\hline
\end{tabular}

Mpar: maternal parity; YS: birth year-season effects;

LEA: loin eye area; D90KG : days to $90 \mathrm{~kg}$; BF : back fat thickness; LEAN : lean meat content

$* * *: \mathrm{P}<0.001 * *: \mathrm{P}<0.01 *: \mathrm{P}<0.05 \mathrm{NS}:$ non significant

Table 5. Least square means and standard errors for productive traits by sex and breeds in a swine herd of Korea

\begin{tabular}{ccccc}
\hline & LEA & D90KG & BF & LEAN \\
\hline \hline Sex & & & & \\
Female & $30.53 \pm 0.13^{\mathrm{a}}$ & $157.11 \pm 0.60^{\mathrm{a}}$ & $12.92 \pm 0.08^{\mathrm{a}}$ & $59.28 \pm 0.11^{\mathrm{b}}$ \\
Male & $29.20 \pm 0.14^{\mathrm{b}}$ & $150.99 \pm 0.62^{\mathrm{b}}$ & $11.62 \pm 0.09^{\mathrm{b}}$ & $60.05 \pm 0.11^{\mathrm{a}}$ \\
\hline Breed & & & \\
LL & $29.57 \pm 0.15^{\mathrm{b}}$ & $155.53 \pm 0.69^{\mathrm{a}}$ & $13.01 \pm 0.10^{\mathrm{a}}$ & $58.80 \pm 0.12^{\mathrm{c}}$ \\
YY & $30.09 \pm 0.13^{\mathrm{a}}$ & $154.79 \pm 0.60^{\mathrm{a}}$ & $12.28 \pm 0.08^{\mathrm{b}}$ & $59.65 \pm 0.10^{\mathrm{b}}$ \\
DD & $29.93 \pm 0.14^{\mathrm{b}}$ & $151.83 \pm 0.62^{\mathrm{b}}$ & $11.53 \pm 0.09^{\mathrm{c}}$ & $60.53 \pm 0.11^{\mathrm{a}}$ \\
\hline
\end{tabular}

LL = Landrace; YY = Large white; DD = Duroc

NBA : number of piglets born alive; NW : number of weaned piglet;

LEA : loin eye area; D90KG : days to $90 \mathrm{~kg}$; BF : back fat thickness; LEAN : lean meat content

Mean in the same column with different superscript differ significantly $(\mathrm{P}<0.05)$

Table 6. Estimates for genetic parameters of reproductive and productive traits on multiple traits mixed model in a swine herd of Korea

\begin{tabular}{ccccccc}
\hline & NBA & NW & LEA & D90KG & BF & LEAN \\
\hline \hline Direct effect & & & & & & \\
NBA & $\mathbf{0 . 0 7}$ & 0.14 & -0.02 & -0.17 & 0.06 & -0.13 \\
NW & 0.14 & $\mathbf{0 . 0 3}$ & -0.01 & -0.20 & 0.17 & -0.18 \\
LEA & 0.01 & -0.01 & $\mathbf{0 . 1 9}$ & 0.16 & 0.04 & 0.35 \\
D90KG & 0.02 & -0.021 & 0.137 & $\mathbf{0 . 3 9}$ & 0.00 & 0.05 \\
BF & 0.01 & 0.021 & -0.03 & 0.07 & $\mathbf{0 . 3 6}$ & -0.42 \\
LEAN & -0.01 & -0.018 & 0.36 & 0.04 & -0.61 & $\mathbf{0 . 4 3}$ \\
\hline Maternal effect & & & & & & \\
NBA & $\mathbf{0 . 0 2}$ & 0.06 & & & & \\
NW & & $\mathbf{0 . 0 2}$ & & & & \\
\hline
\end{tabular}

Heritabilities are on diagonals and Genetic correlations are upper diagonals and phenotypic correlations are below diagonals NBA : number of piglets born alive; NW : number of weaned piglet;

LEA : loin eye area; D90KG : days to $90 \mathrm{~kg}$; BF : back fat thickness; LEAN : lean meat content.

보였으나, 실산자수와 이유자돈수간의 유전상관 추정치는 상가적 유전효과에서 0.10 및 모체 유전효과에서는 -0.36 로 모체 유전효 과에서만 상반되는 결과를 나타냈다. 또한 등심단면적, $90 \mathrm{~kg}$ 도달 일령, 등지방두께와 정육률의 유전력은 Jeon and Hong (1989), Lo 등(1992), Xuewei and Kennedy (1994) 및 Choi 등 (2004)의 보
고에 비해 낮았으며, 등지방두께, $90 \mathrm{~kg}$ 도달일령 유전력은 keele 등 (1988) 및 park (1995)의 보고에 비해 높았다. 또한 번식형질과 산육형질 유전상관은 등지방두께를 제외한 나머지 산육형질에서 번 식형질과의 부의 상관을 보여, 번식형질 또는 산육형질을 독자적으 로 개량하고자 할 때, 부의 관계가 있는 형질과의 유전적 관계를 
Cho et al. ; Genetic Parameter Estimates for Reproductive and Productive Traits of Pig in a Herd

고려한 개량목표 설정이 필요할 것으로 사료된다.

$$
\text { 요 약 }
$$

본 연구는 국내 특정 종돈장에서 보유하고 있는 종돈에 대한 번 식형질 및 산육형질들에 대한 유전변이를 추정하고자 연구를 실시 하였다. 본 분석에 이용된 자료는 2000년부터 2008년까지 개량을 진행한 국내 모종돈장에 있는 돼지(Landrace, Large white, Duroc) 2,447 두에서 조사된 9,886복의 번식자료 (실산자수, 이유자 돈수)와 10,181 두의 산육검정자료 (등심단면적, $90 \mathrm{~kg}$ 도달일령, 등 지방두께, 정육률)을 이용하여 분석을 실시하였다. 번식형질 및 산 육형질에 적합한 모형을 찾기 위해 분산분석을 실시하였으며, 그 결과 번식형질에서 품종효과, 교배웅돈효과, 산차효과, 분만시 년도 -계절효과, 산육형질에서 품종효과, 분만시 년도-계절효과, 성의 효과, 모산차 등이 환경요인으로 작용하는 것으로 나타나 이들을 혼합모형방정식에 적합시켜 유전모수를 추정하였다. 그 결과, 번식 형질의 실산자수에 대한 유전력은 0.07 , 모체 유전효과에 대한 유 전력은 0.02 로 추정되었고 이유자돈수의 유전력은 0.03 , 모체 유전 효과에서 0.02 로 추정되었으며 이들 두 형질 간의 유전상관은 0.14 , 모체 유전효과에 대한 상관은 0.06 로 추정되었다. 또한 등심 면적의 경우 $0.19,90 \mathrm{~kg}$ 도달일령은 0.39 , 등지방두께 및 정육률 은 각각 0.36 및 0.43 으로 번식형질에 비해 높은 유전력을 나타내 는 것으로 추정되었다. 또한 등심단면적과 등지방두께 간에는 0.04 로 유전적 상관관계가 없으며, 등심단면적과 정육률 간에는 0.35 로 중도의 유전적 상관관계를 갖는 것으로 추정되었다. 반면에 등지방 두께와 정육률 간은 -0.42 로 중도의 부의 상관관계를 나타냈으며, 등지방두께와 $90 \mathrm{~kg}$ 도달일령 간에는 유전상관이 없는 것 $(0.00)$ 으 로 추정되었다. 또한 번식형질과 산육형질 간 유전상관은 등지방두 께를 제외한 나머지 산육형질에서 번식형질과의 부의 상관을 보여, 번식형질 또는 산육형질을 독자적으로 개량하고자 할 때, 부의 관 계가 있는 형질과의 유전적 관계를 고려한 개량목표 설정이 필요할 것으로 사료된다.

(주제어: 유전모수, 번식형질, 생산형질, 돼지, 돼지육종)

$$
\text { 사 사 }
$$

본 연구는 2011년 농림수산식품부 농림기술연구과제 (과제번호 309022-5)의 일환으로 수행하였음

\section{인 용 문 헌}

Chen, P., Baas, T. J., Marby, J. W., Koehler, K. J. and Dekkers, J.

C. M. 2003a. Genetic parameters and trends for litter traits in U.S. Yorkshire, Duroc, Hampshire and Landrace pigs. J. Anim. Sci. 81:46.

Chen, P., Baas, T. J., Mabry, J. W. and Koehler, K. J. 2003b.
Genetic correlations between lean growth and litter traits in U.S. Yorkshire, Duroc, Hampshire, and Landrace pigs. J. Anim. Sci. 81:1700-1705.

Choi, C. S., Lee, I. J., Cho, K. H., Seo, K. S. and Lee, J. G. 2004. Estimation of Genetic Parameters for Economic Traits in Swine. Korean. J. Anim. Sci \& Technol. 46(2):145-154.

Clutter, A. C. and Brascamp, E. W. 1998. Genetics of performance traits. Pages 427-462 in The Genetics of the Pig. M. F. Rothschild and A. Ruvinsky, ed. CAB international, NY.

Ducos, A. and Bidanel, J. P. 1996. Genetic correlations between production and reproduction traits measured on the farm, in Large White and French Landrace pig breeds. J. Anim. Breed. Genet. 113:493-504.

Holm, B., Bakken, M., Klemetsdal, G. and Vangen, O. 2004. Genetic correlations between reproduction and production traits in swine. J. Anim. Sci. 82:3458-3464.

Jeon, J. T. and Hong, K. C. 1989. Breeding and Reproduction : Estimate of Genetic Parameters and Factors Having Effect on the Selection of Foundation Stock in Linebreeding of Pig. Korean. J. Anim. Sci \& Technol. 31:373.

Keele, J. W., Johnson, R. K., Young, L. D. and Socha, T. E. 1988. Comparison of methods of predicting breeding values of swine. J. Anim. Sci. 66:3040.

Lo, L. L., McLaren, D. G., Mckeith, F. K., Fernando, R. L. and Novakofski, J. 1992. Genetic analyses of growth, real-time ultrasound, carcass, and pork quality traits in Duroc and Landrace pigs: II Heritabilities and correlations. J. Anim. Sci. 70:2387.

Misztal, I. 2001. REMLF90 family pakage. http:// hce.ads.uga.edu.

National Institute of Animal Science(NIAS), R.D.A. 2010. Report of estimation of breeding value in swine.

Park, B. H. 1995. Study on estimation of genetic parameters and effect of sex for economic traits in the landrace breed of swine. Unpublished master dissertation, University of Seoul, Seoul.

Patterson, H. D. and Thompson, R. 1971. Recovery of inter-block information when block sizes are unequal. Biometrika 58(3): 545-554.

Rydhmer, L. 2000. Genetics of sow reproduction, including puberty, oestrus, pregnancy, farrowing and lactation. Livest. Prod. Sci. 66:1-12.

Su, G., Lund, M. S. and Sorensen, D. 2007. Selection for litter size at day five to improve litter size at weaning and piglet survival rate.

Xuewei, Li and Kennedy, B. W. 1994. Genetic parameters for growth rate and back fat in Canadian Yorkshire, Landrace, Duroc, and Hampshire pigs, J. Anim. Sci. 1994. 72:1450-1454.

(Received Oct. 17, 2011; Revised Nov. 20, 2011; Accepted Dec. 10, 2011) 